Supplement of Nat. Hazards Earth Syst. Sci., 21, 3573-3598, 2021

https://doi.org/10.5194/nhess-21-3573-2021-supplement

(C) Author(s) 2021. CC BY 4.0 License.

(c) (1)

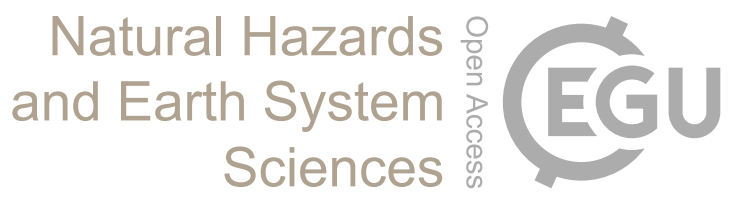

Supplement of

\title{
Using high-resolution regional climate models to estimate return levels of daily extreme precipitation over Bavaria
}

\author{
Benjamin Poschlod \\ Correspondence to: Benjamin Poschlod (benjamin.poschlod@npv-bgd.bayern.de)
}

The copyright of individual parts of the supplement might differ from the article licence. 


\section{Supplementary material}
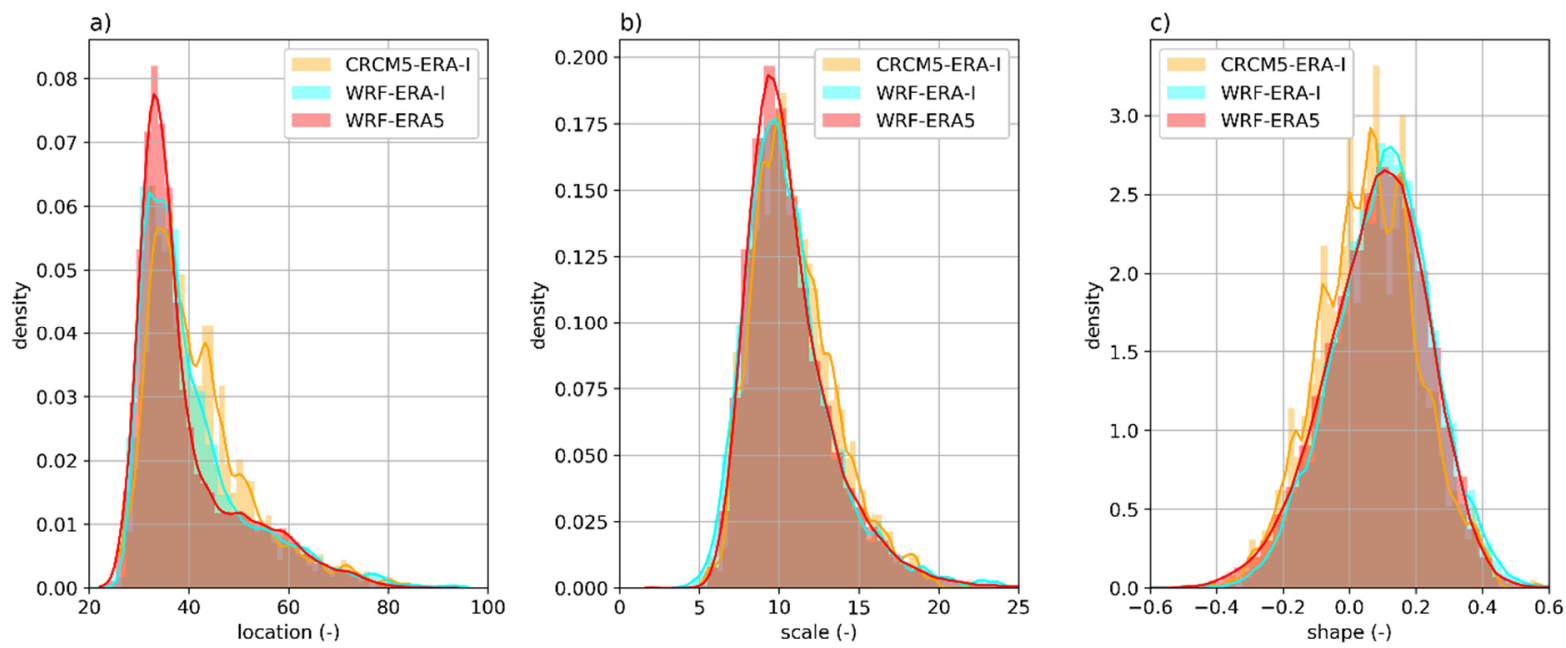

Figure S1: Histograms of location (a), scale (b), and shape (c) parameters of the GEV models fitted via L-Moments for the CRCM5-ERA-Interim, WRF-ERA-Interim, and WRF-ERA-5. Gaussian kernel density estimates are plotted to enhance readability.
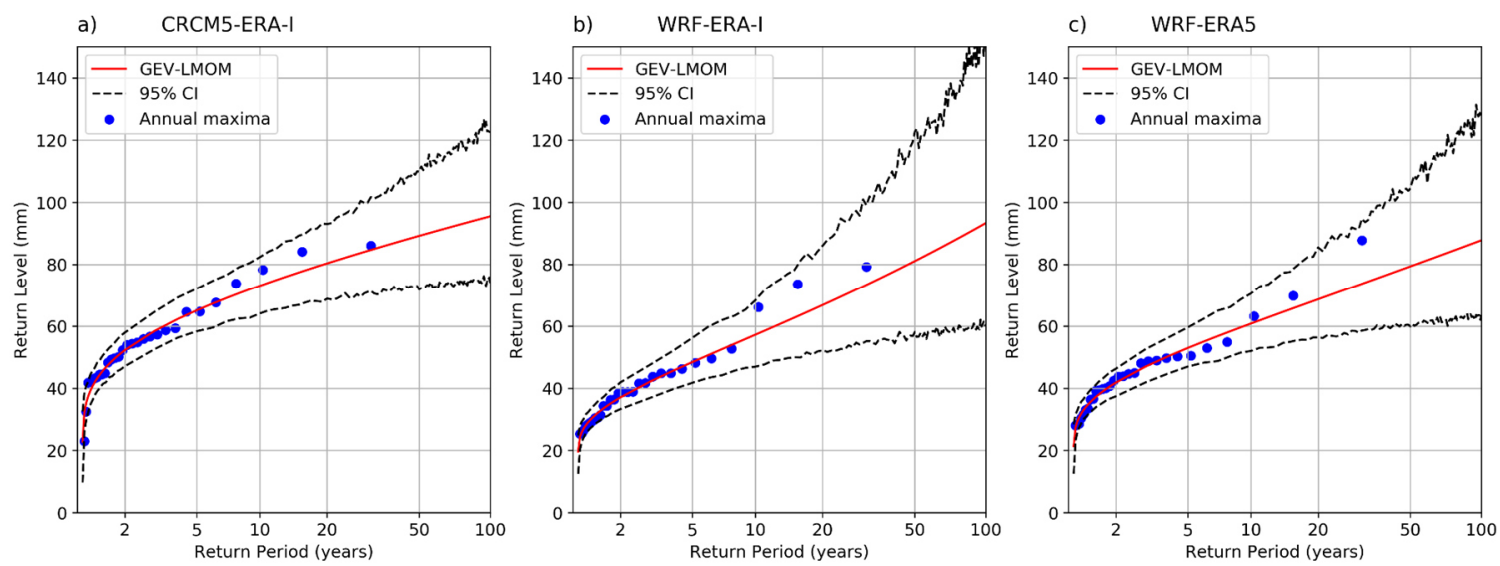

Figure S2: Return levels corresponding to the GEV model fitted via L-Moments (solid red line) for the three climate model setups ( $a, b, c)$ at the grid cell of Munich. The annual maxima (blue dots) are plotted for comparison via Weibull plotting positions. The $95 \%$ confidence interval computed via bootstrapping (1000 iterations) is provided (dashed black line). 

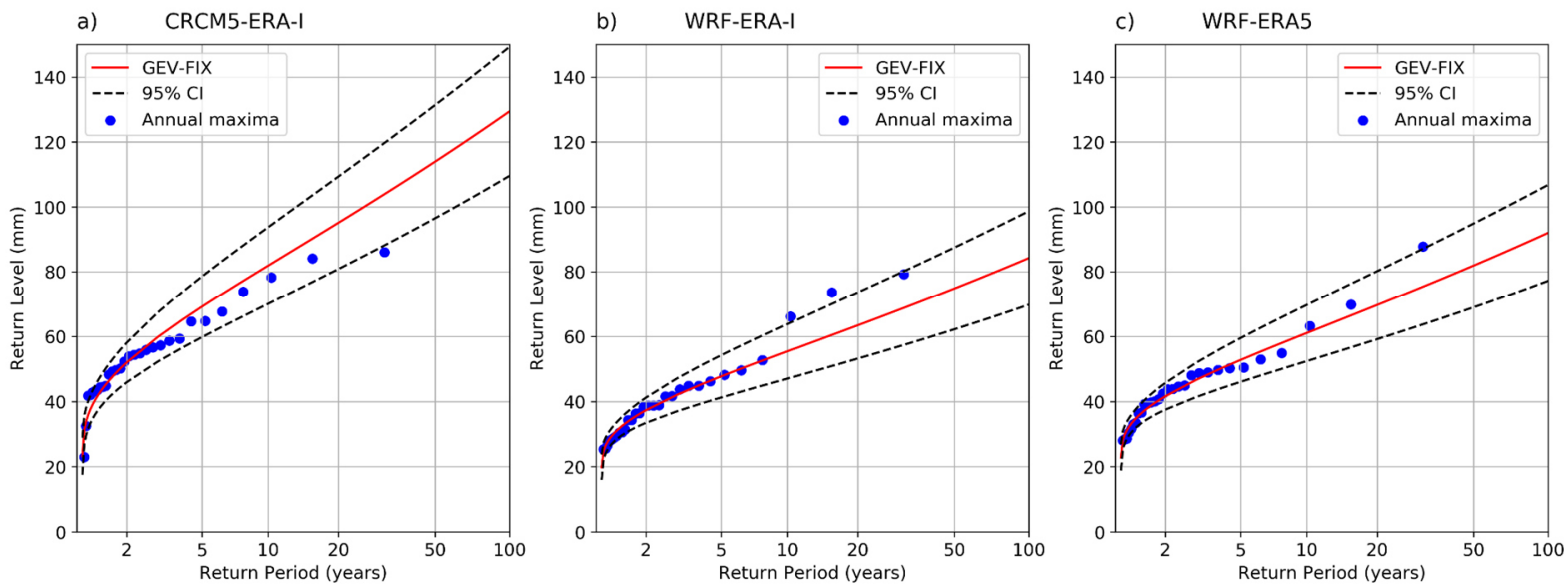

Figure S3: Return levels corresponding to the fitted GEV model with fixed shape parameter (solid red line) for the three climate model setups (a, b, c) at the grid cell of Munich. The annual maxima (blue dots) are plotted for comparison via Weibull plotting positions. The $95 \%$ confidence interval computed via delta method is provided (dashed black line).
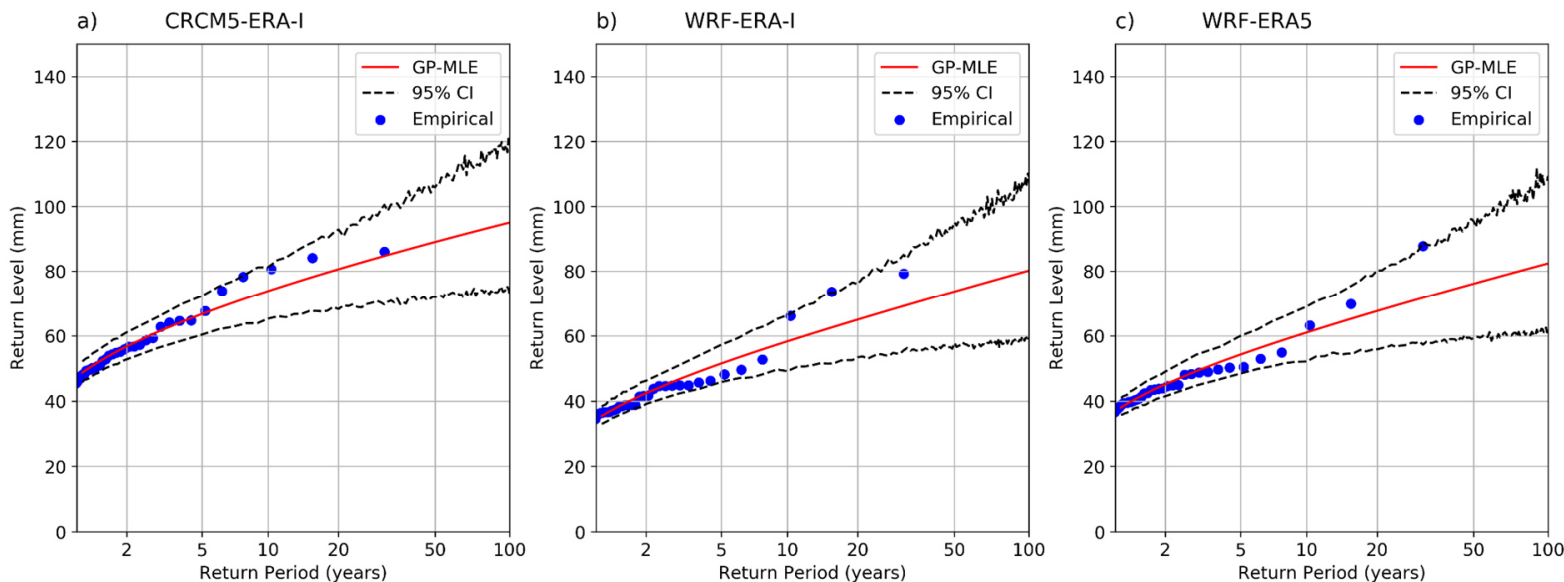

Figure S4: Return levels corresponding to the GP model fitted via MLE (solid red line) for the three climate model setups (a, b, c) at the grid cell of Munich. The events over the threshold (blue dots) are plotted for comparison via Weibull plotting positions. The $95 \%$ confidence interval computed via bootstrapping (1000 iterations) is provided (dashed black line). 
a) CRCM5-ERA-I

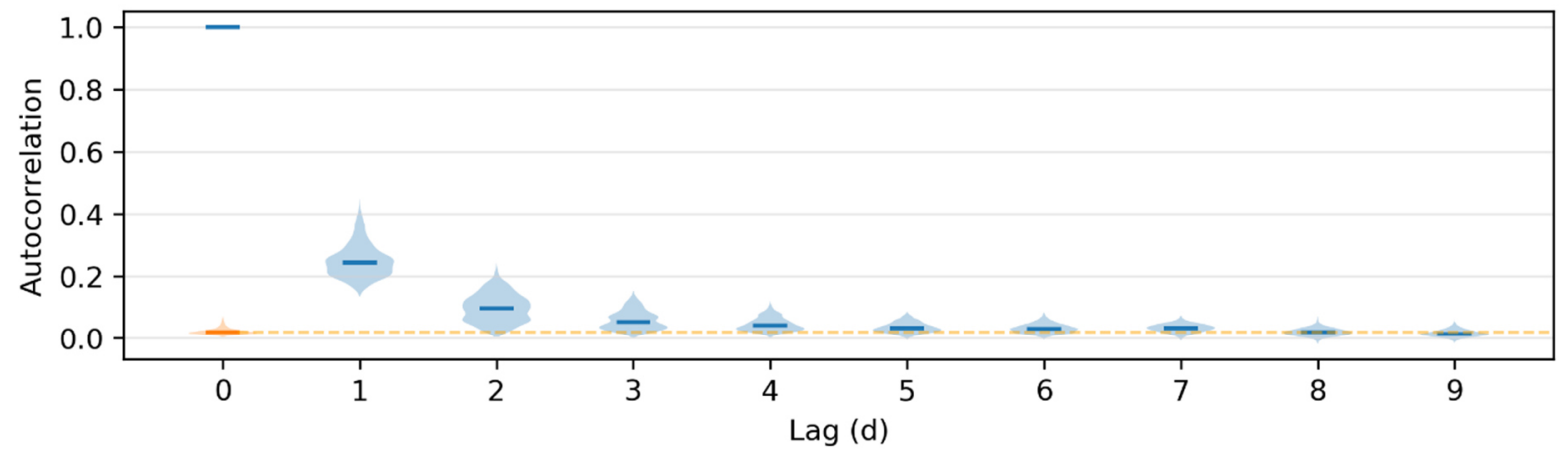

b) WRF-ERA-I

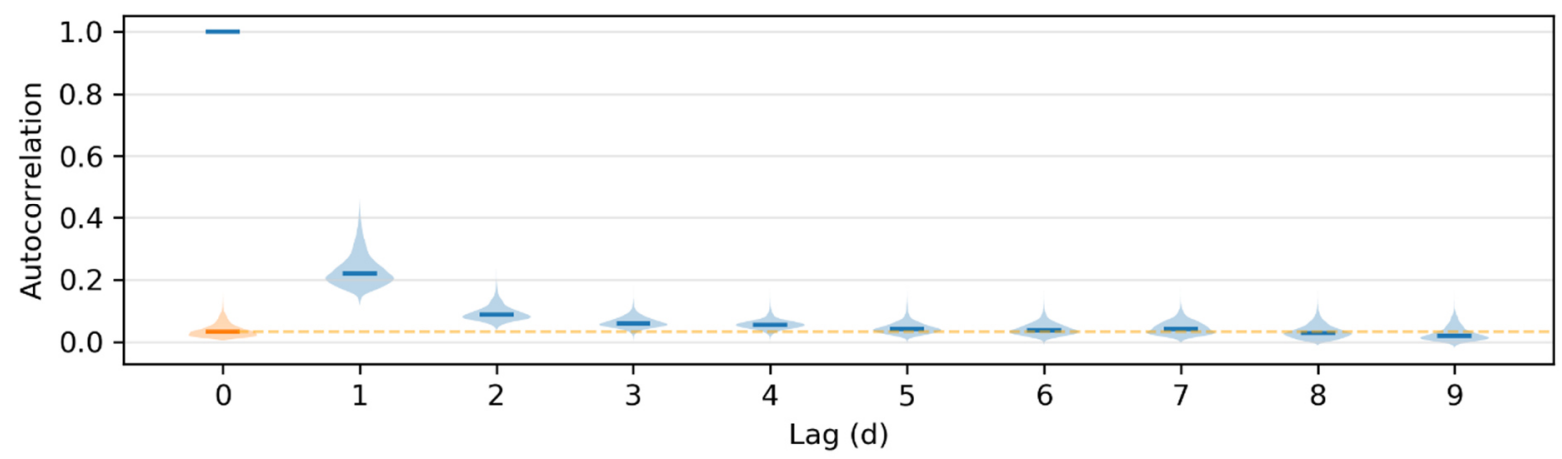

c) WRF-ERA5

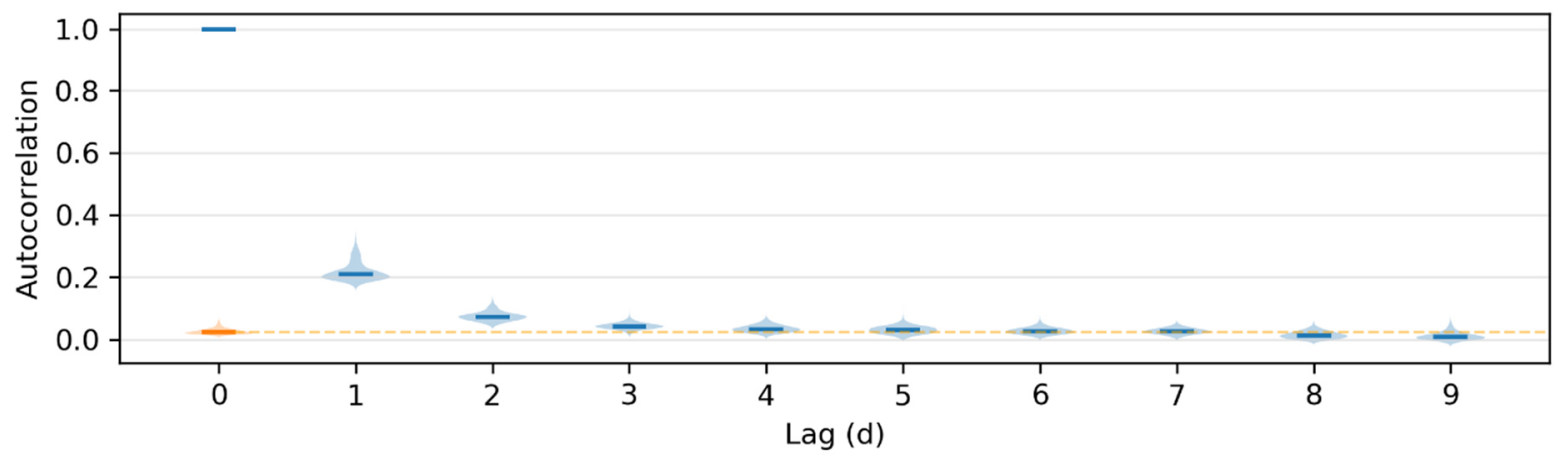

Figure S5: Violin plots with medians (blue lines) of the serial autocorrelation of daily rainfall for the three climate model setups $(a, b, c)$ over the study area. The orange violin plots indicate the threshold, which is applied to decluster the daily rainfall timeseries into "ordinary events". It amounts to the $75^{\text {th }}$ percentile of autocorrelation between 10 and 30 days, which is assumed to be uncorrelated noise. The minimal distance between ordinary events equals the time lag when the temporal autocorrelation first drops below the $75^{\text {th }}$ percentile threshold. 

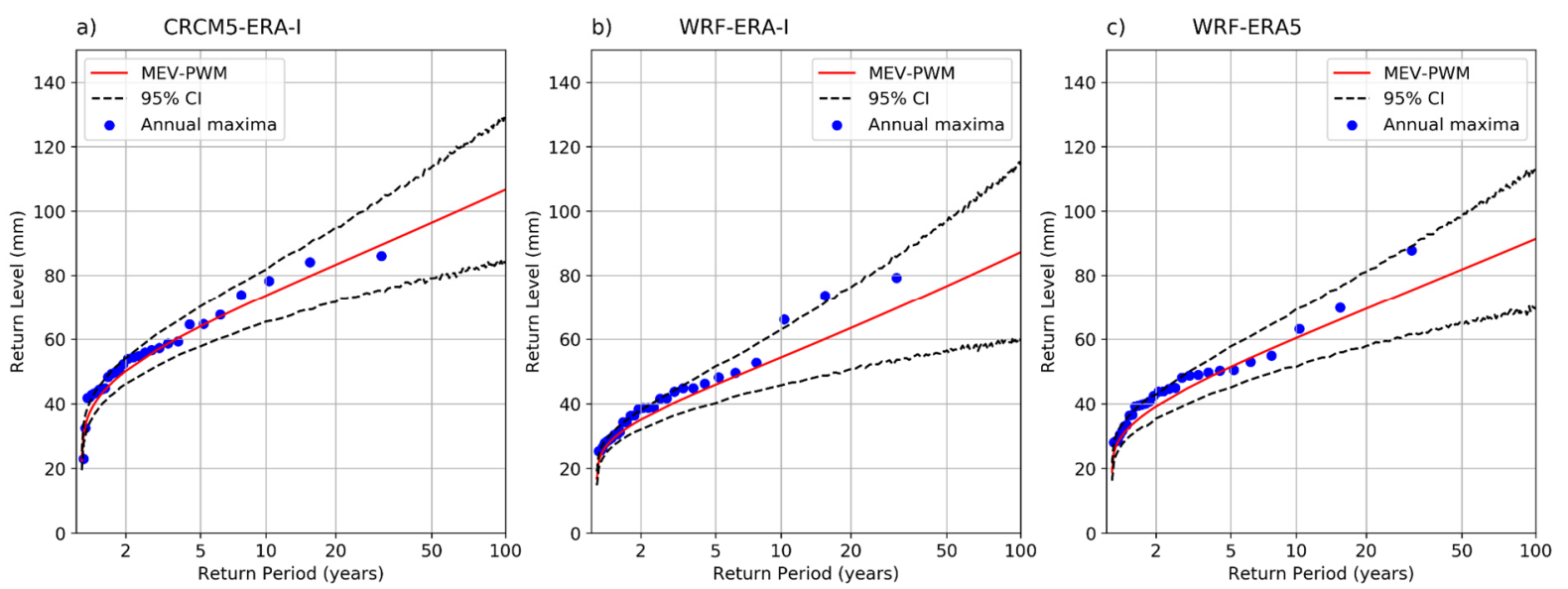

Figure S6: Return levels corresponding to the fitted MEV model fitted via PWM (solid red line) for the three climate model setups (a, b, c) at the grid cell of Munich. The annual maxima (blue dots) are plotted for comparison via Weibull plotting positions. The $95 \%$ confidence interval computed via bootstrapping (1000 iterations) is provided (dashed black line). 
a) CRCM5-ERA-I GEV-LMOM

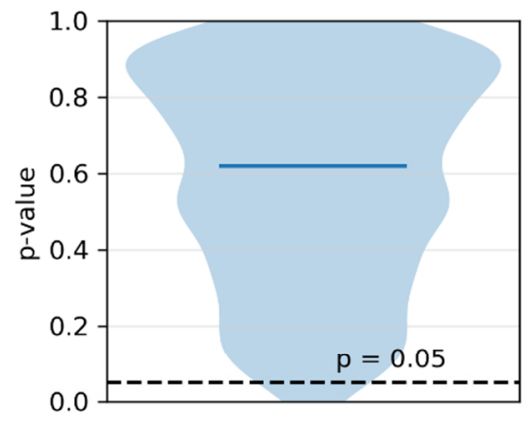

d) CRCM5-ERA-I GEV-FIX

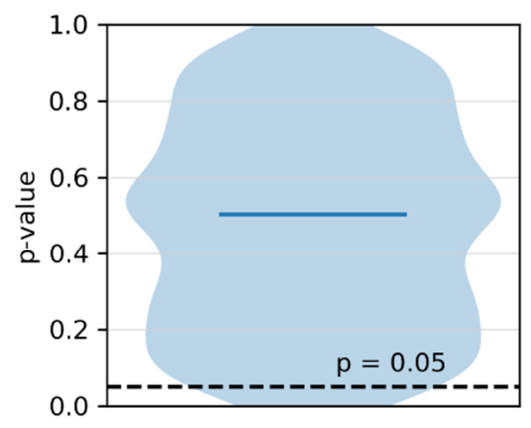

g) CRCM5-ERA-I GP-MLE

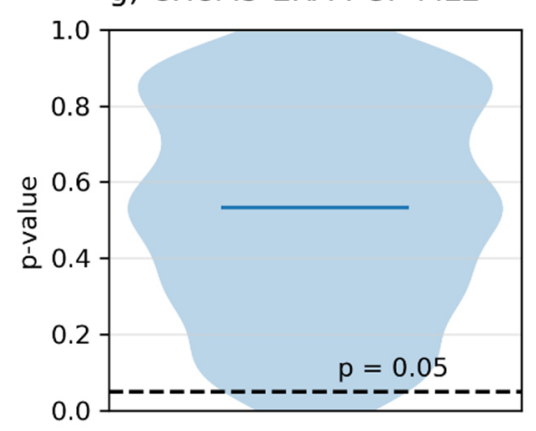

j) CRCM5-ERA-I MEV-PWM

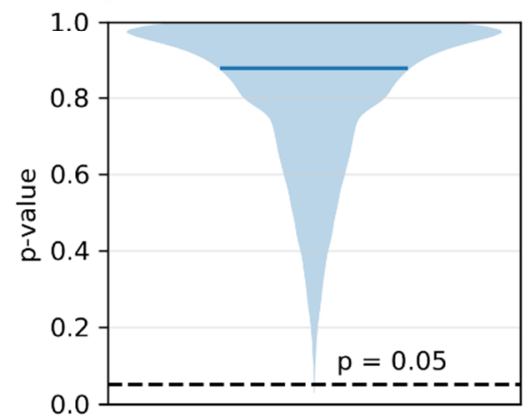

b) WRF-ERA-I GEV-LMOM

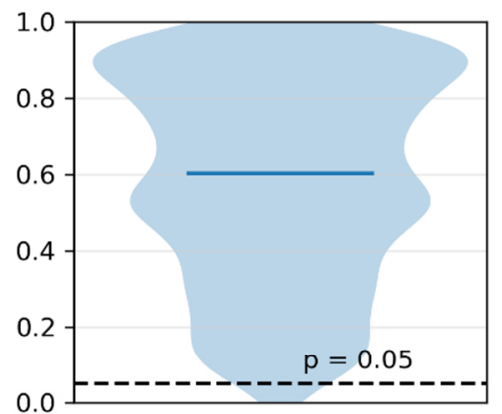

e) WRF-ERA-I GEV-FIX

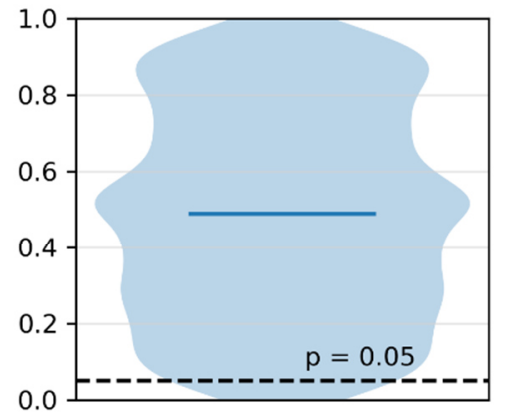

h) WRF-ERA-I GP-MLE

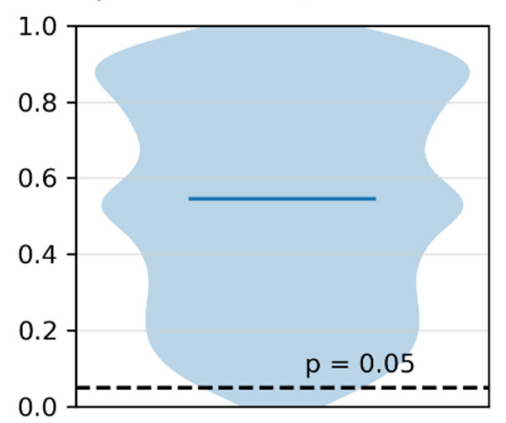

k) WRF-ERA-I MEV-PWM

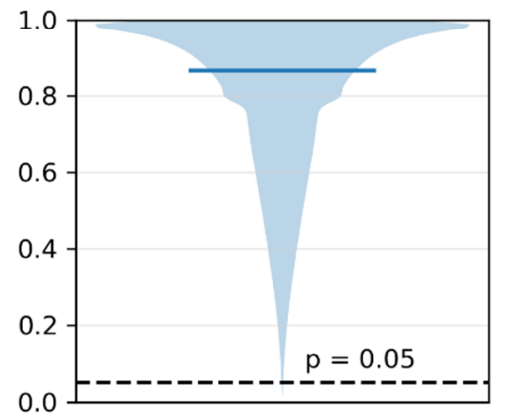

c) WRF-ERA5 GEV-LMOM

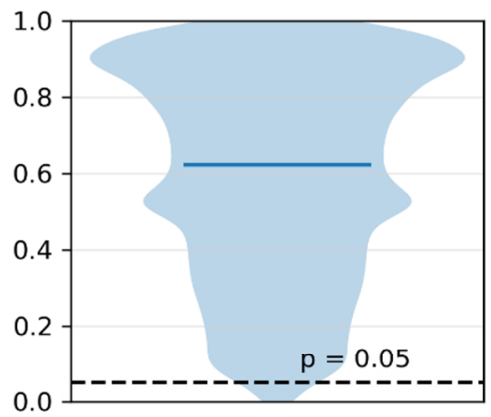

f) WRF-ERA5 GEV-FIX

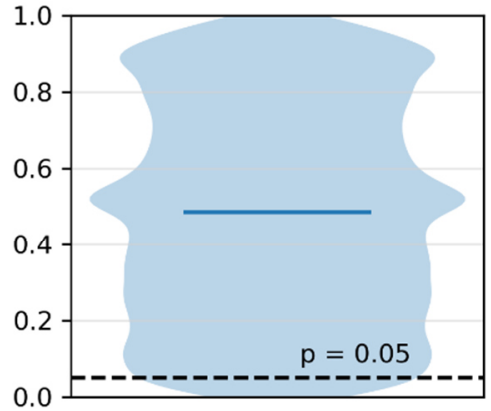

i) WRF-ERA5 GP-MLE

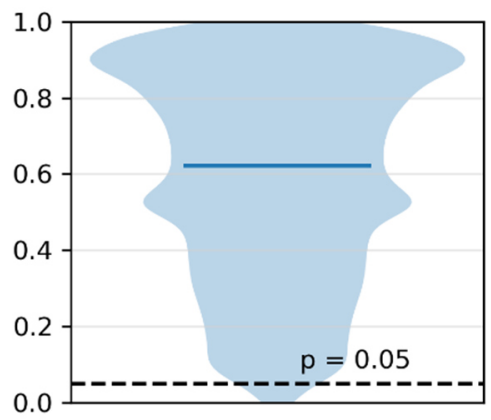

I) WRF-ERA5 MEV-PWM

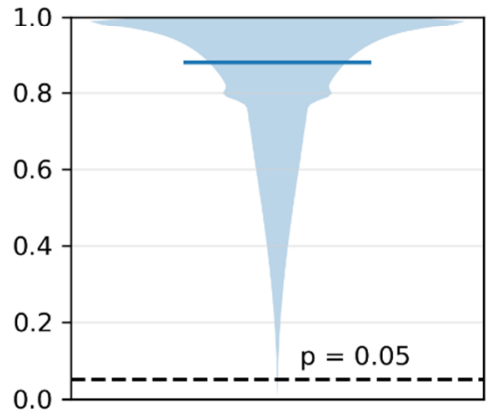

Figure S7: Violin plots with medians (blue line) of the p-value of the goodness-of-fit tests for the three climate model setups (columns) and four different EVT approaches (rows). For the GEV and GP models (a-i), the p-values of the Anderson-Darling test over all grid cells is provided. For the MEV-PWM ( $\mathrm{j}-1)$, the Kolmogorov-Smirnov test was performed by fitting the Weibull distribution to every year at each grid cell. All resulting p-values contribute to the violin plots. 

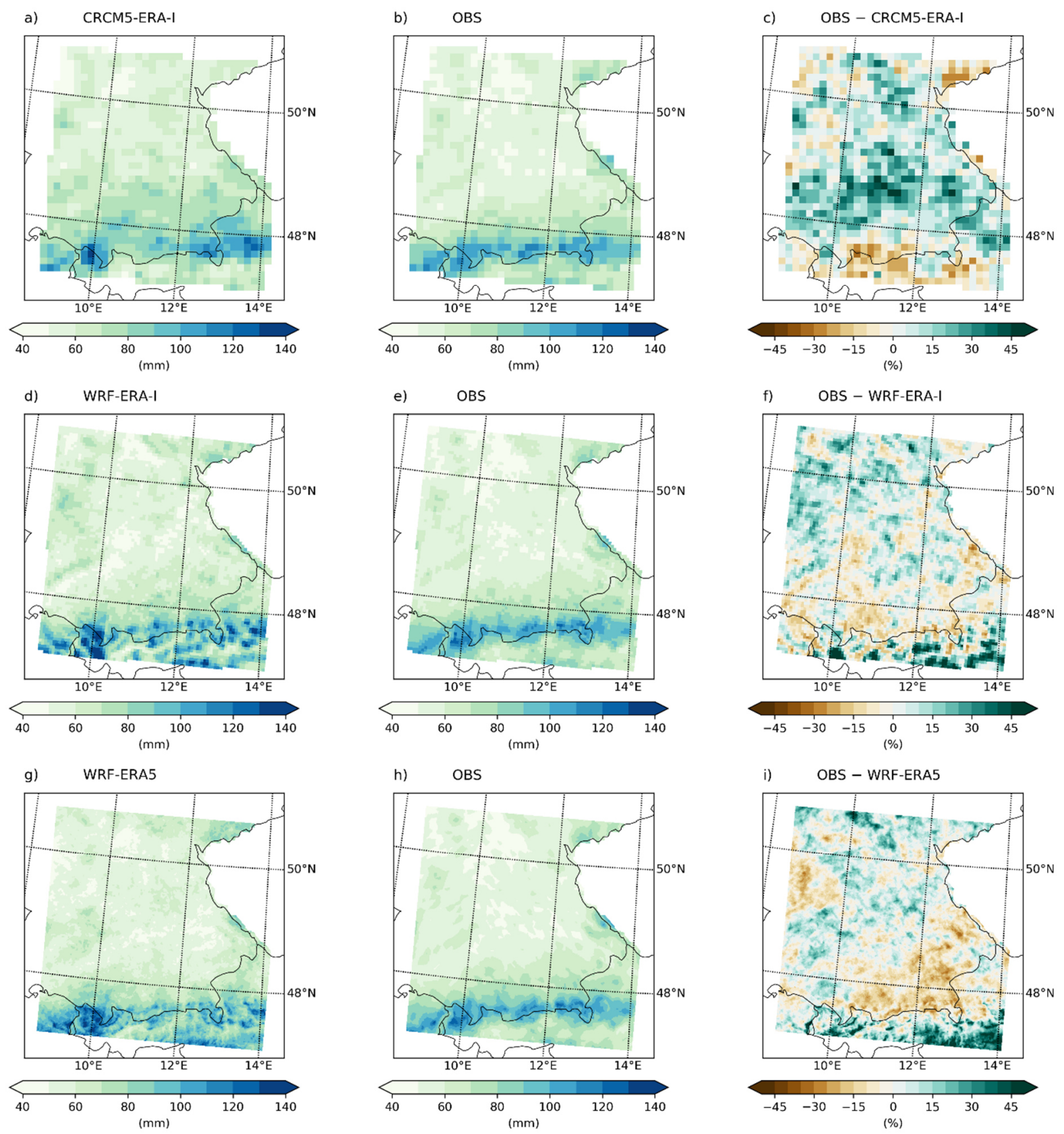

Figure S8: 10-year rainfall return levels applying GEV-FIX based on the CRCM5-ERA-Interim (a), WRF-ERAInterim (d), WRF-ERA5 (g). The middle column ( $b, e, h)$ shows the observational product bilinearly interpolated to the respective climate model grid. The right column (c, f, i) provides the percentage difference calculated as climate model return level minus observational return level. 

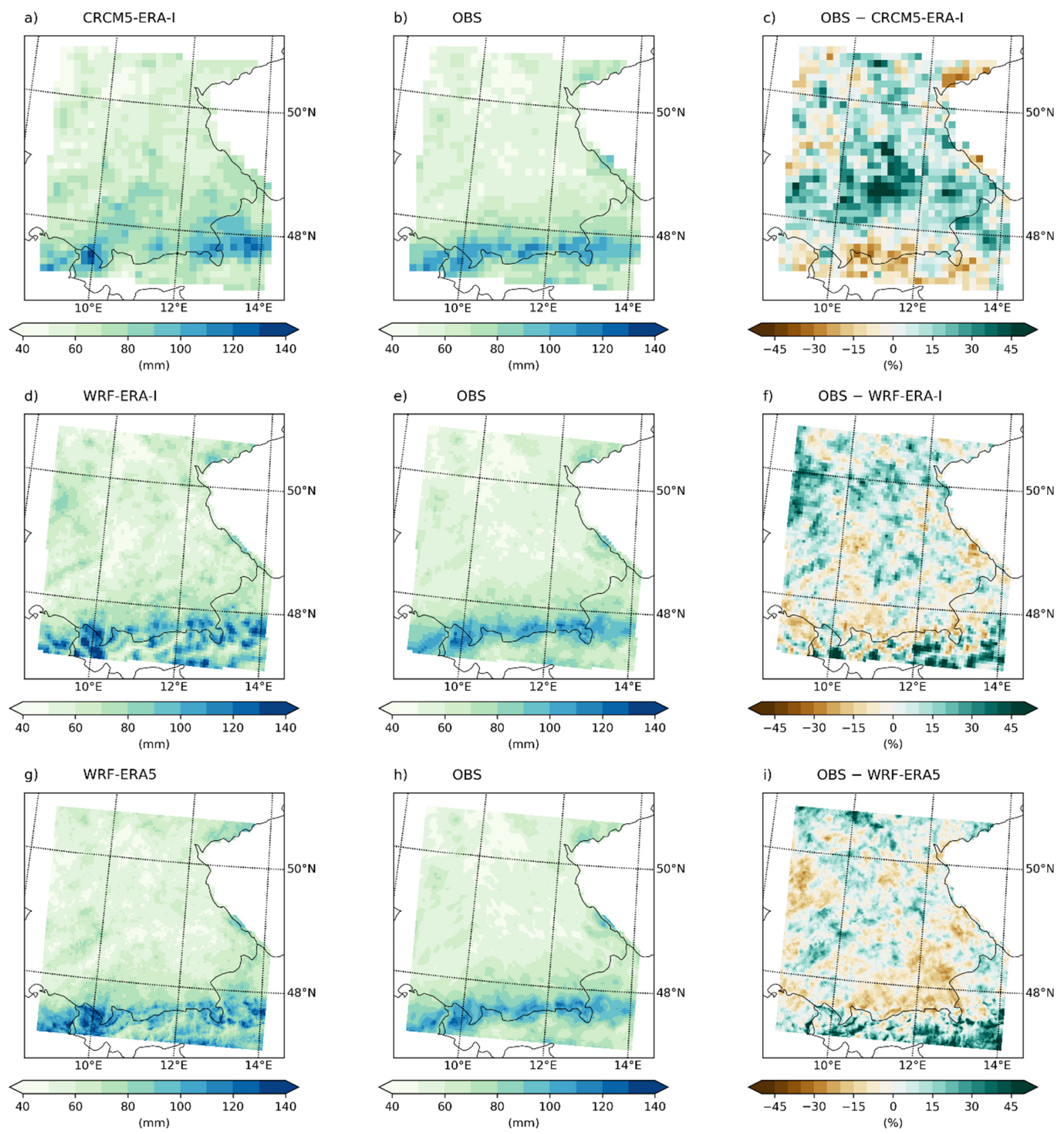

Figure S9: 10-year rainfall return levels applying GP-MLE based on the CRCM5-ERA-Interim (a), WRF-ERAInterim (d), WRF-ERA5 (g). The middle column ( $b, e, h)$ shows the observational product bilinearly interpolated to the respective climate model grid. The right column (c, f, i) provides the percentage difference calculated as climate model return level minus observational return level. 

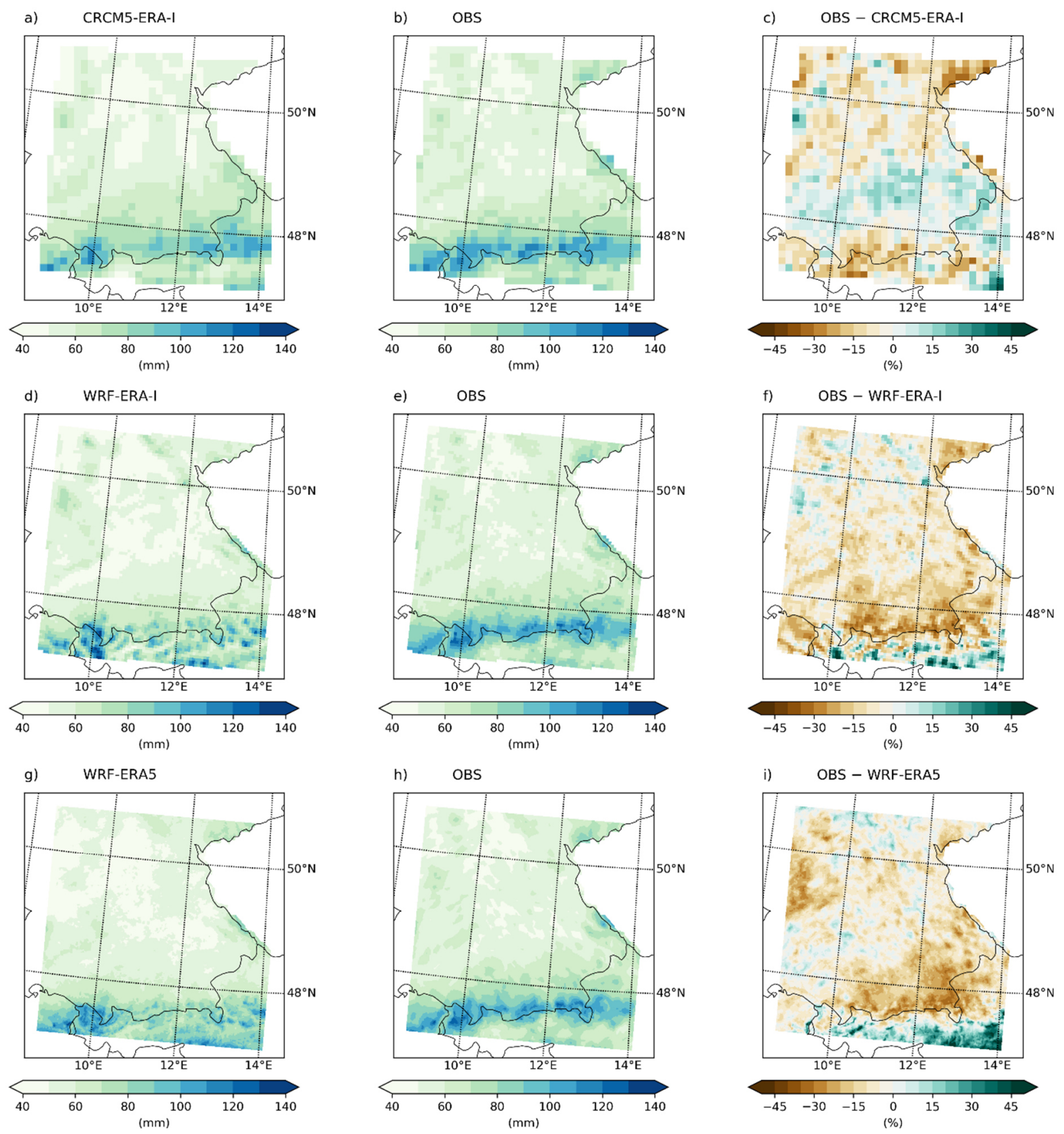

Figure S10: 10-year rainfall return levels applying MEV-PWM based on the CRCM5-ERA-Interim (a), WRFERA-Interim (d), WRF-ERA5 (g). The middle column (b, e, h) shows the observational product bilinearly interpolated to the respective climate model grid. The right column (c, f, i) provides the percentage difference calculated as climate model return level minus observational return level. 

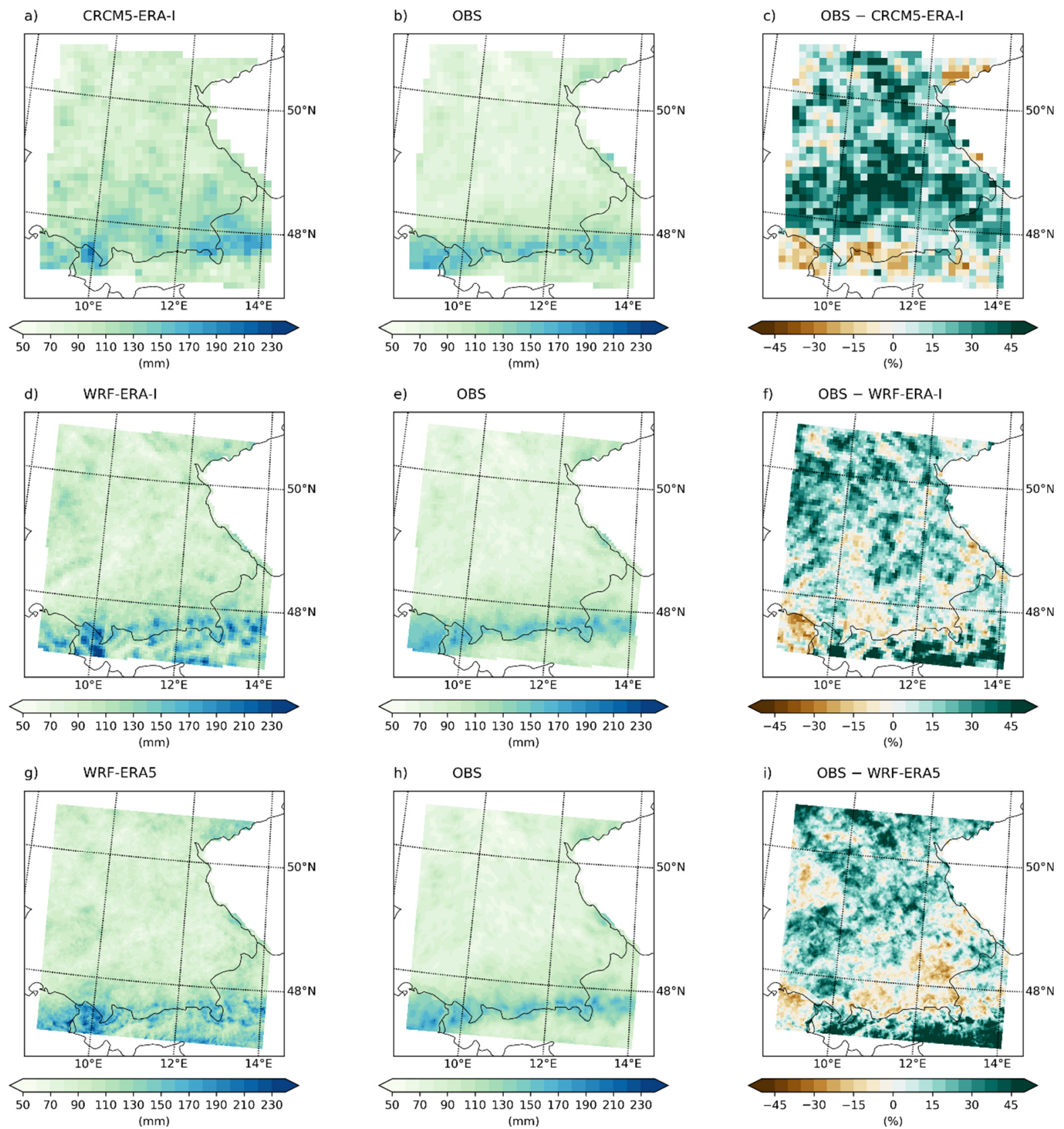

Figure S11: 100-year rainfall return levels applying GEV-FIX based on the CRCM5-ERA-Interim (a), WRF-ERAInterim (d), WRF-ERA5 (g). The middle column ( $b, e, h)$ shows the observational product bilinearly interpolated to the respective climate model grid. The right column (c, f, i) provides the percentage difference calculated as climate model return level minus observational return level. 

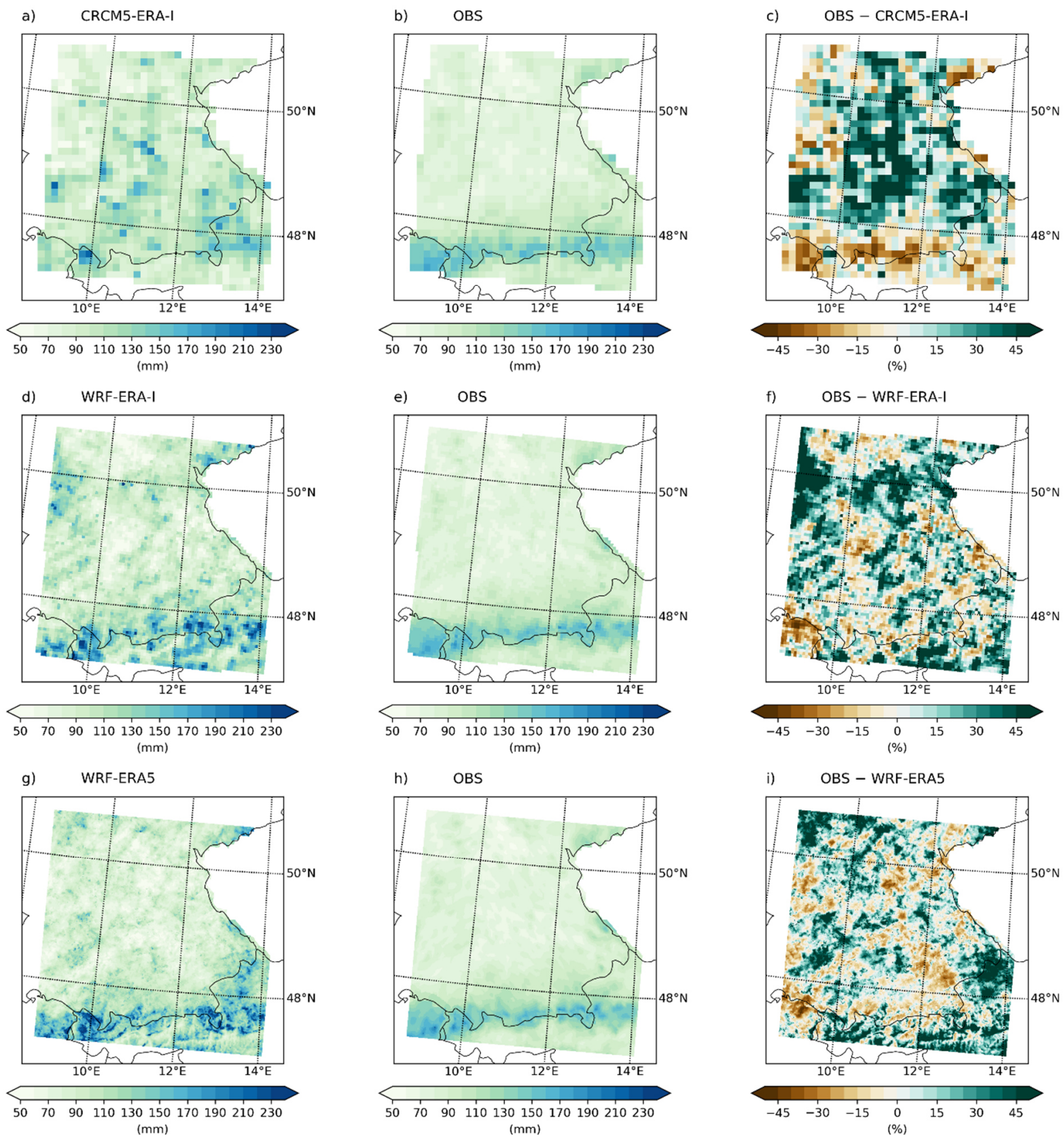

Figure S12: 100-year rainfall return levels applying GP-MLE based on the CRCM5-ERA-Interim (a), WRF-ERAInterim (d), WRF-ERA5 (g). The middle column ( $b, e, h)$ shows the observational product bilinearly interpolated to the respective climate model grid. The right column (c, f, i) provides the percentage difference calculated as climate model return level minus observational return level. 

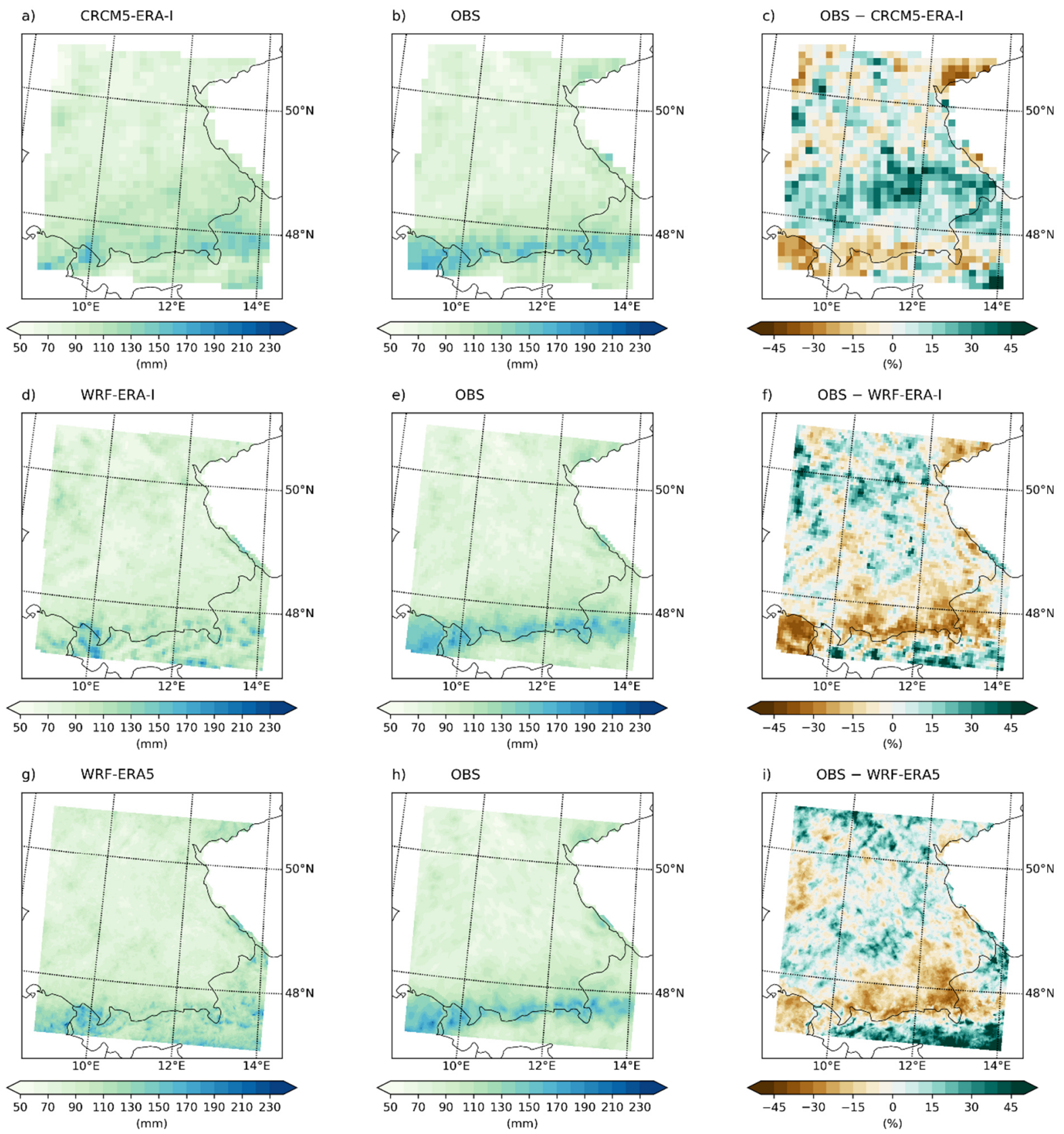

Figure S13: 100-year rainfall return levels applying MEV-PWM based on the CRCM5-ERA-Interim (a), WRFERA-Interim (d), WRF-ERA5 (g). The middle column (b, e, h) shows the observational product bilinearly interpolated to the respective climate model grid. The right column (c, f, i) provides the percentage difference calculated as climate model return level minus observational return level. 


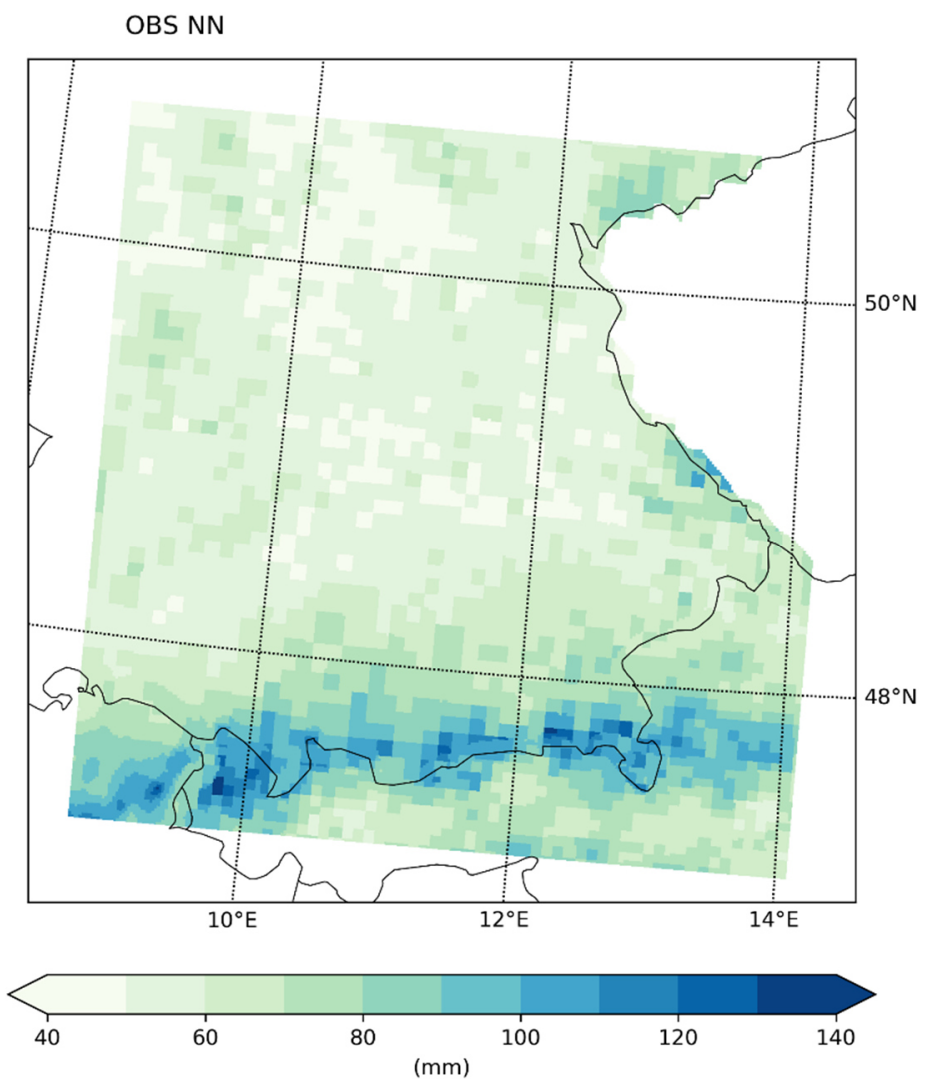

Figure S14: Observational 10-year return levels based on the German, Austrian, and Swiss data at original resolution. 
a) $1999 / 05 / 20$ CRCM5-ERA-1

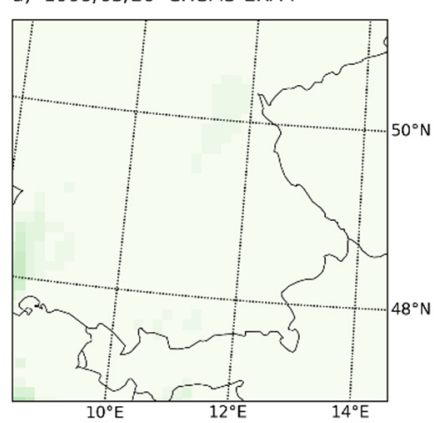

e) $1999 / 05 / 21$ CRCM5-ERA-I

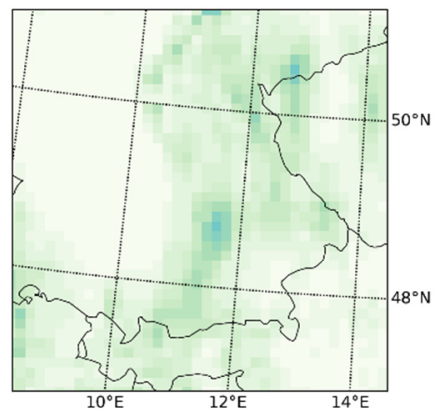

i) $1999 / 05 / 22$ CRCM5-ERA-I

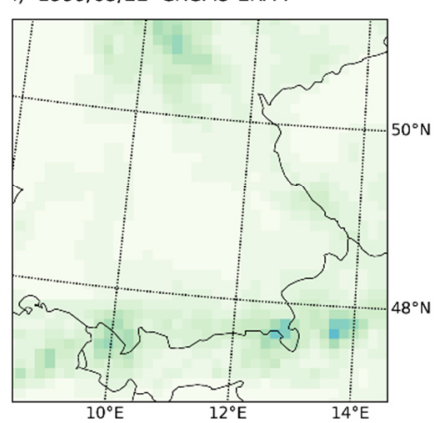

b) $1999 / 05 / 20$ WRF-ERA-I

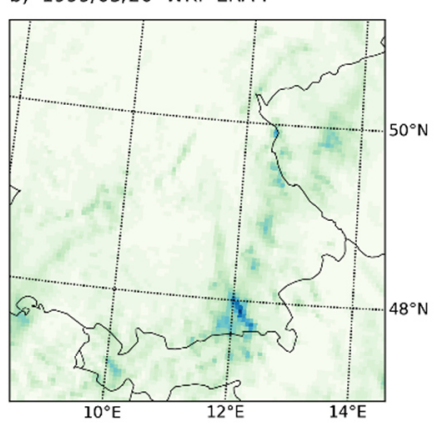

f) $1999 / 05 / 21$ WRF-ERA-I

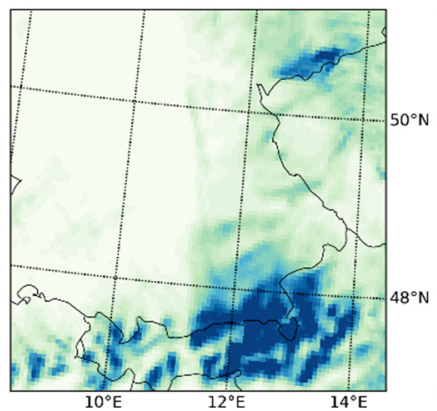

c) $1999 / 05 / 20$ WRF-ERA5

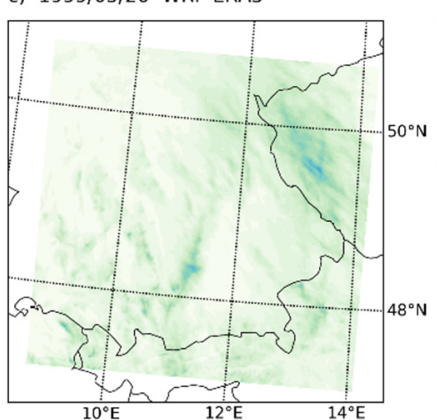

g) $1999 / 05 / 21$ WRF-ERA5

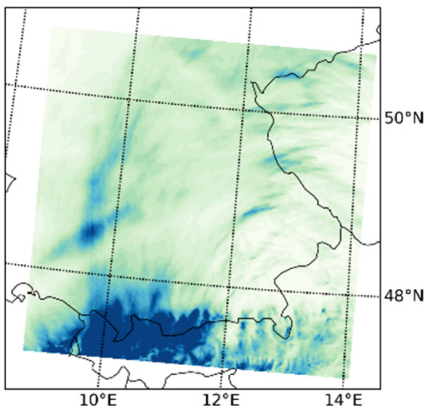

d) $1999 / 05 / 20$ OBS

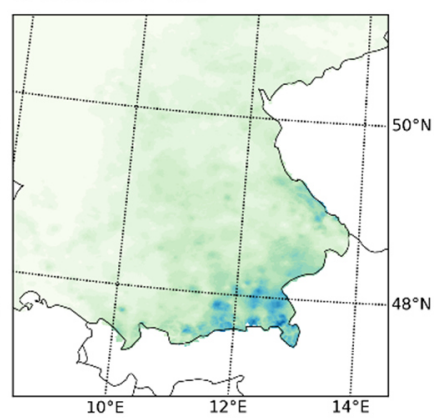

h) $1999 / 05 / 21$ OBS

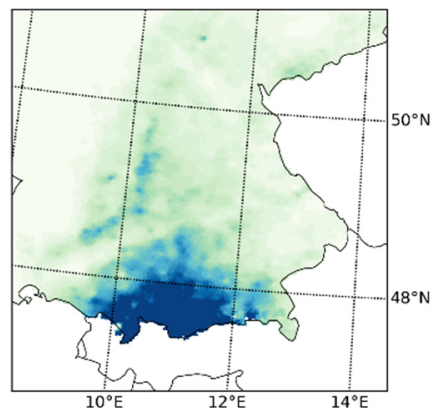

j) $1999 / 05 / 22$ WRF-ERA-I

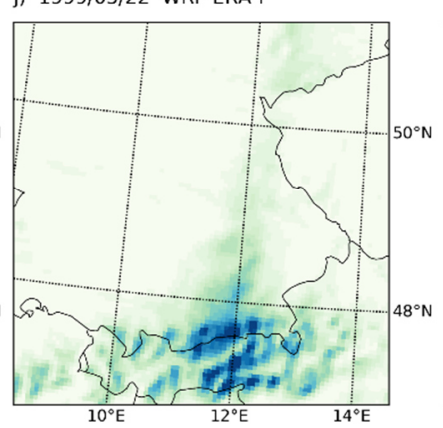

k) $1999 / 05 / 22$ WRF-ERA5

I) $1999 / 05 / 22$ OBS
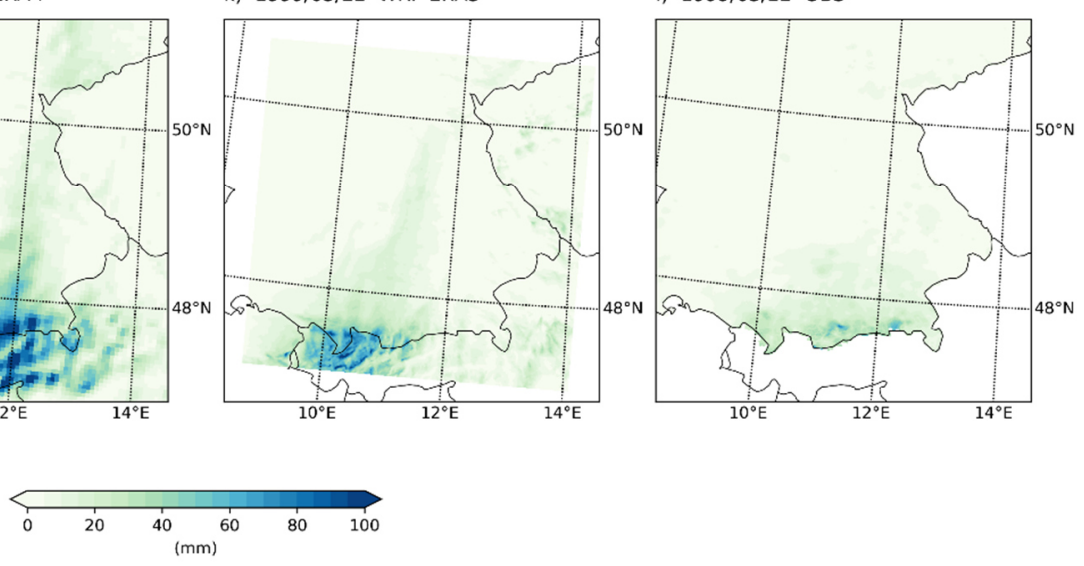

Figure S15: Daily rainfall sums for 20 - 22 May 1999 from CRCM5-ERA-Interim (a, e, i), WRF-ERA-Interim (b, $\mathrm{f}, \mathrm{j}$ ), WRF-ERA5 (c, g, k) and the observational product REGNIE (d, h, l). Observational data for Austria and Switzerland is not openly available. Each dataset is shown in its native spatial resolution. 
a) $2005 / 08 / 21$ CRCM5-ERA-I

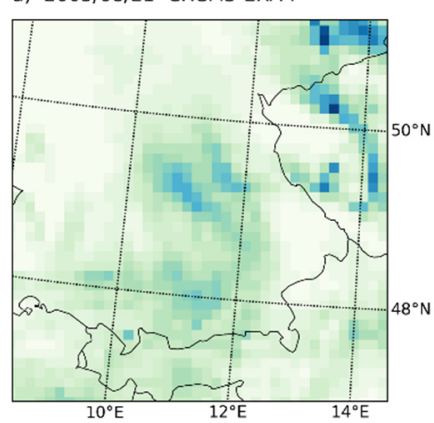

e) $2005 / 08 / 22$ CRCM5-ERA-I

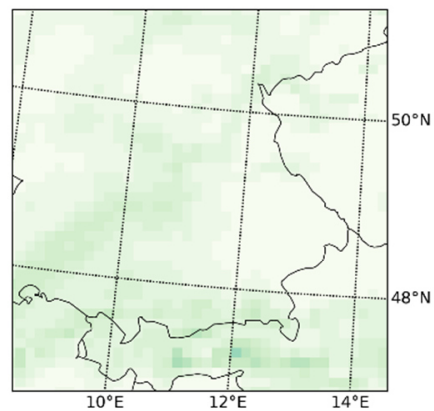

i) $2005 / 08 / 23$ CRCM5-ERA-I

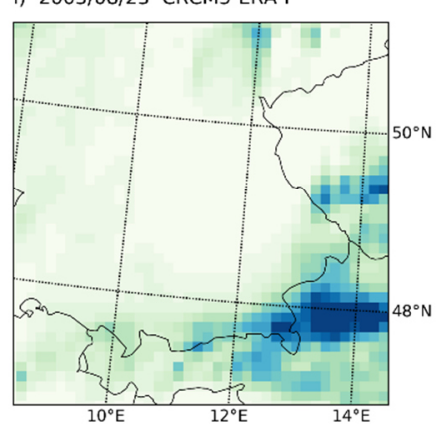

b) $2005 / 08 / 21$ WRF-ERA-I

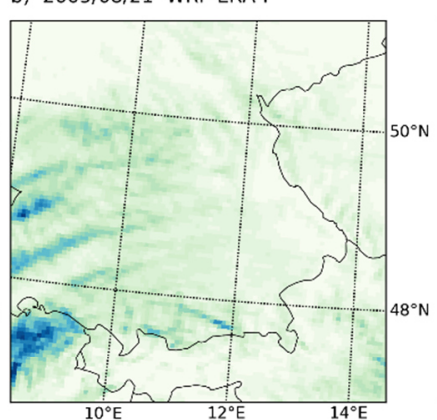

f) $2005 / 08 / 22$ WRF-ERA-I

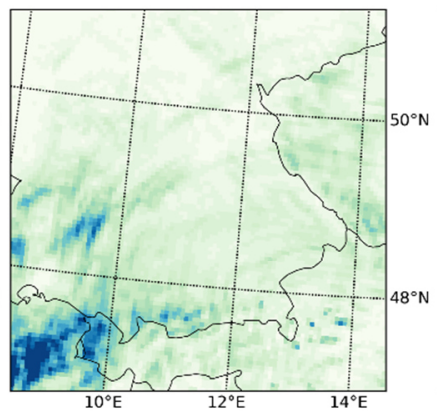

j) $2005 / 08 / 23$ WRF-ERA-I

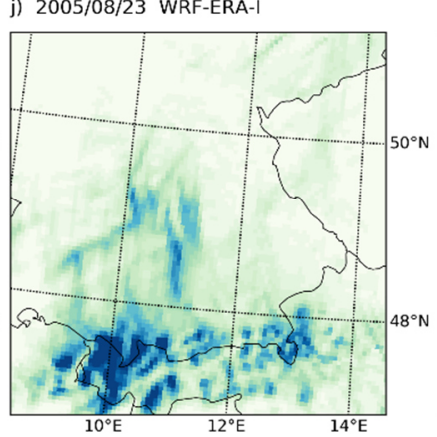

c) $2005 / 08 / 21$ WRF-ERA5

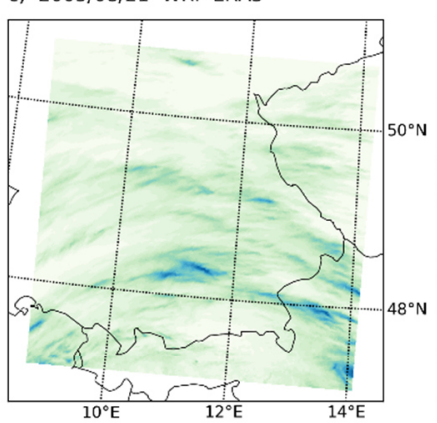

g) $2005 / 08 / 22$ WRF-ERA5

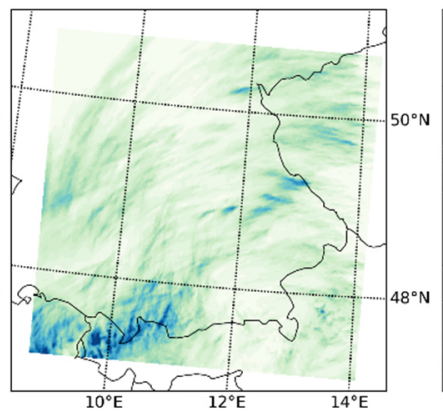

k) $2005 / 08 / 23$ WRF-ERA5

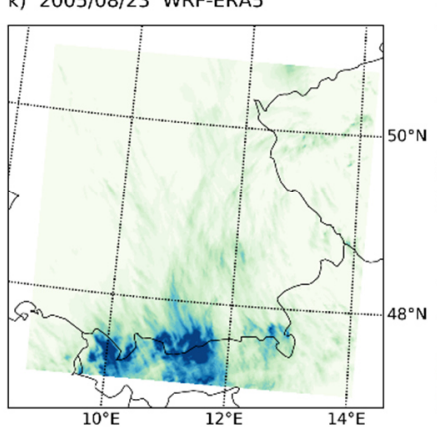

d) $2005 / 08 / 21$ OBS

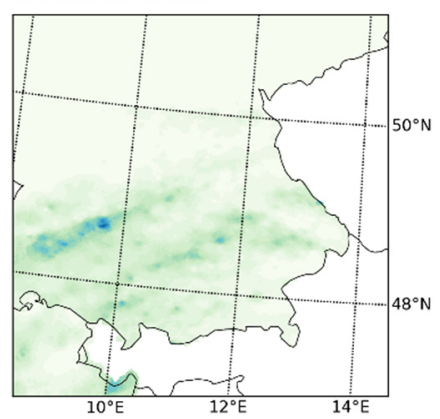

h) $2005 / 08 / 22 \mathrm{OBS}$

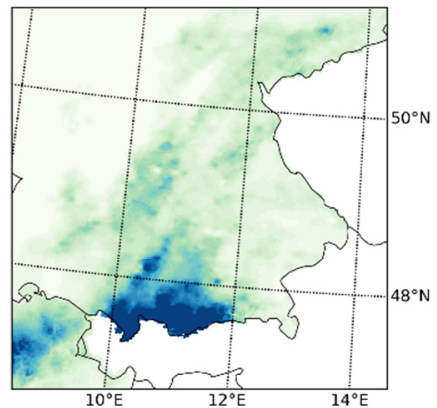

I) $2005 / 08 / 23$ OBS

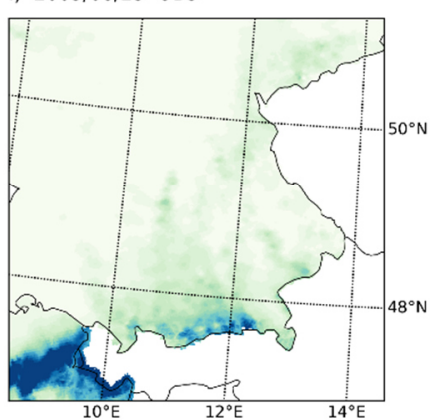

Figure S16: Daily rainfall sums for 21 - 23 August 2005 from CRCM5-ERA-Interim (a, e, i), WRF-ERA-Interim (b, f, j), WRF-ERA5 (c, g, k) and the observational products REGNIE and RhiResD (d, h, l). Observational data for Austria is not openly available. Each dataset is shown in its native spatial resolution. 